\title{
Isotherm Studies of Mono, Divalent and Trivalent Cationic Soaps onto Derived $\mathrm{Fe}_{2} \mathrm{O}_{3}$ Adsorbent Surface
}

\author{
Etim E. $\mathbf{E}^{1^{*}}$, Itodo, A. U. ${ }^{2}$, Mbakara, I. $\mathbf{E}^{3}$ \\ ${ }^{1}$ Department of Chemical Sciences, Federal University, PMB 1020, Wukari, Nigeria \\ ${ }^{2}$ Department of Chemistry and Agro-Chemical Technology, University of Agriculture Makurdi, Nigeria \\ ${ }^{3}$ Department of Chemistry, University of Ibadan, Ibadan
}

*Corresponding Author: Etim E. E, Department of Chemical Sciences, Federal University, Wukari, Nigeria

\begin{abstract}
Mono, di and tri valent cationic soap of two oils (shear butter; Butryspermum Parkii and rubber seeds; Hevea Brasiliensis) labeled as $M^{x}-Y$ soaps were used as adsorbates for the adsorption studies. Initial adsorbates concentration ranged from Co values of 0.20 to $3.0 \mathrm{mmol} / \mathrm{L}$ which after equilibration, corresponds to various attained equilibrium concentrations that depends on the metallic soap uptake under investigation at a fixed temperature of $27^{\circ} \mathrm{C}$. Generated data were treated with five isotherm models, namely Langmuir, Freundlich, Temkin, BET and Dubinin Radushkevich isotherms. Applicability test via its coefficient was adopted in explaining the best fit isotherm. Sorption capacity (qe,qm,qs), intensity ( $k)$, surface coverage ( $n$, $\left.R_{L}\right)$, binding affinity characteristics $\left[K_{F}(\mathrm{~L} / \mathrm{g}), K_{a}(\mathrm{~g} / \mathrm{mmol}), A, b(\mathrm{~L} / \mathrm{mmol}), C_{B E T}(\mathrm{~L} / \mathrm{g})\right]$ as well as the energy parameter constants $B_{D}$ and $E(K J / m m o l)$ deduced from the isotherms were all used in measuring the sorption phenomenon and performance of derived home based metallic ore (hematite; $\alpha-\mathrm{Fe}_{2} \mathrm{O}_{3}$ ). Equilibrium conditions were attained using sets of batch reactors for experimental runs. The sorption performance of metallic soaps uptake varied according to the nature of metallic soaps, difference in surface ions and ionic charge concentrations of each adsorbate.
\end{abstract}

Keywords: Hematite, metallic soaps, Langmuir, Freundlich, Temkin, BET, Dubinin Radushkevich

\section{INTRODUCTION}

Concern about environmental protection has increased over the years from a global viewpoint. To date, the prevalence of adsorption separation in the environmental chemistry remains an aesthetic attention and consideration abroad the nations, owning to its low initial cost, simplicity of design, ease of operation, insensitivity to toxic substances and complete removal of pollutants even from dilute solutions (Foo and Hameed, 2010). Numerous adsorbents for the removal of heavy metals from aqueous solutions are in various stages of research. The main goal for most of this research is to develop low-cost and environmentally friendly materials for the removal of heavy metals from contaminated groundwater, surface water, and drinking water (Hafez and Yousef, 2012). Materials that have ion exchange sites are expected to be able to efficiently remove heavy metals from water. Iron oxides, especially in the micro/nano structured forms, are good candidates for the removal of toxic heavy metal ions from water due to their structural properties.

Many adsorption materials have been investigated for the removal of heavy metal ions from water. Sorbents that have been studied include natural and artificial materials such as clay mineral (Gu et al., 2010, Omer et al., 2003, Abollino et al., 2003), pillared clay, sago waste, cassava waste, banana pith, peanut skins, medicago sativa (Alfalfa), and sphagnum moss peat, carbon-nanomaterials (Li et al., 2003, Li et al., 2002, Gao et al., 2009, Guo et al., 2008, Debnath and Ghosh, 2009, O'Reilly and Hochella, 2003). Recently the emphasis is on the use of efficient, yet low cost and environmentally friendly adsorbents. Micro/nano iron oxides such as goethite $(\alpha-\mathrm{FeOOH})$ and hematite $(\alpha-\mathrm{Fe} 2 \mathrm{O} 3)$ fall under this category. The benefits of using these micro/nano materials may derive from their increased affinity due to their high surface area and the presence of surface functional groups which makes them appropriate to interact with heavy metal ions. Theoretically, materials that have high surface area and ion exchange sites are expected to be able to efficiently remove heavy metal ions from water. Iron oxides are ideal for the removal of heavy metal ions from water due to their strong mechanical structure that can sustain water flow for extended periods of time and their low cost (Hafez and Yousef, 2012). 
Sorption equilibria provide fundamental physicochemical data for evaluating the applicability of sorption processes as a unit operation. Sorption equilibrium is usually described by an isotherm equation whose parameters express the surface properties and affinity of the sorbent, at a fixed temperature and $\mathrm{pH}$. Thus an accurate mathematical description of the equilibrium isotherm, preferably based on a correct sorption mechanism, is essential to the effective design of sorption systems (Ho et al., 2002). In this study, four two-parameter equations - the Freundlich, Langmuir, Temkin and Dubinin-Radushkevich isotherms - and a multilayer physisorption isotherm - BrunauerEmett-Teller (BET) were examined for their ability to model the equilibrium sorption data.

Freundlich isotherm is the earliest known relationship describing the non-ideal and reversible adsorption, not restricted to the formation of monolayer. This empirical model can be applied to multilayer adsorption, with non-uniform distribution of adsorption heat and affinities over the heterogeneous surface (Foo and Hameed, 2010). The linear form of the Freundlich isotherm is expressed by the following equation:

$\log \mathrm{qe}=\log \mathrm{K}_{\mathrm{F}}+1 / \mathrm{n} \log \mathrm{C}_{\mathrm{e}}$

Where qe is the amount of adsorbate in the adsorbent at equilibrium $(\mathrm{mg} / \mathrm{g}), \mathrm{K}_{\mathrm{F}}$ is the Freundlich isotherm constant $(\mathrm{mg} / \mathrm{g})(\mathrm{dm} 3 / \mathrm{g})^{\mathrm{n}}$ related to adsorption capacity, $\mathrm{n}$ adsorption intensity and $\mathrm{C}_{\mathrm{e}}$ equilibrium concentration $(\mathrm{mg} / \mathrm{L})$.

In 1916 Langmuir developed a theoretical equilibrium isotherm relating the amount of gas sorbed on a surface to the pressure of the gas (Langmuir, 1916). The Langmuir model is probably the best known and most widely applied sorption isotherm. It has produced good agreement with a wide variety of experimental data and may be represented as follows:

$1 / \mathrm{q}_{\mathrm{e}}=1 / \mathrm{k}_{\mathrm{a}} \mathrm{q}_{\mathrm{m}} \cdot 1 / \mathrm{C}_{\mathrm{e}}+1 / \mathrm{q}_{\mathrm{m}}$

Where $\mathrm{q}_{\max }$ is the maximum sorption uptake and $\mathrm{b}$ the, Langmuir constant, which establishes the relationship between sorption and desorption rate. According to the Langmuir equation; A plot of $1 / \mathrm{q}_{\mathrm{e}}$ against $1 / \mathrm{C}_{\mathrm{e}}$ gave the slope, $1 / \mathrm{K}_{\mathrm{a}} \mathrm{q}_{\mathrm{m}}$ and intercept, $1 / \mathrm{q}_{\mathrm{m}}$. The model assumes monolayer adsorption onto a surface containing a finite number of adsorption sites of uniform strategies with no transmigration of adsorbate in the plane surface (Hameed et al., 2006).

Temkin isotherm is the early model describing the adsorption of hydrogen onto platinum electrodes within the acidic solutions. The derivation of the isotherm assumes that the fall in the heat of sorption is linear rather than logarithmic, as implied in the Freundlich equation (Gunay et al., 2007). The linear form of the Temkin isotherm is represented as shown in equation 4

$\mathrm{qe}=\mathrm{RT} / \mathrm{b}_{\mathrm{T}} \ln \mathrm{A}_{\mathrm{T}}+\left(\mathrm{RT} / \mathrm{b}_{\mathrm{T}}\right) \ln \mathrm{C}_{\mathrm{e}}$

Where qe is the amount of adsorbate in the adsorbent at equilibrium $(\mathrm{mg} / \mathrm{g}), \mathrm{R}$ is the universal gas constant $(8.314 \mathrm{~J} / \mathrm{mol} \mathrm{K}), \mathrm{b}_{\mathrm{T}}$ is the Temkin isotherm constant, $\mathrm{A}_{\mathrm{T}}$ is the Temkin isotherm equilibrium binding constant $(\mathrm{L} / \mathrm{g})$ and $\mathrm{C}_{\mathrm{e}}$ is the equilibrium concentration $(\mathrm{mg} / \mathrm{L})$.

Dubinin-Radushkevich isotherm is an empirical model initially conceived for the sorption of subcritical vapors onto micropore solids following a pore filling mechanism. It is generally applied to express the adsorption mechanism (Foo and Hameed, 2010) with a Gaussian energy distribution onto a heterogeneous surface. The model has often successfully fitted high solute activities and the intermediate range of concentrations data well, but has unsatisfactory asymptotic properties and does not predict the Henry ${ }^{\text {ees }}$ law at low pressure. The linear form of the isotherm is represented in equation 5 .

$\ln (\mathrm{qe})=\ln (\mathrm{qs})-\mathrm{K}_{\mathrm{ad}} \varepsilon^{2}$

Where $\mathrm{Kad}$ is the Dubinin-Radushkevich isotherm constant (mol2/kJ2), is the DubininRadushkevich isotherm constant and qs is the theoretical isotherm saturation capacity (mg/g).

The best-known approaches to describe the thickness of physically adsorbed films on flat substrates are the Brunauer-Emmett-Teller-BET theory for low coverages and the Frenkel-Halsey-Hill theory for the asymptotic behaviour of thick films (Mecke and Krim, 1996). Brunauer-Emmett-Teller (BET) isotherm is a theoretical equation, most widely applied in the gas-solid equilibrium systems. It was developed to derive multilayer adsorption systems with relative pressure ranges from 0.05 to 0.30 
corresponding to a monolayer coverage lying between 0.50 and 1.50 (Foo and Hameed, 2010). The linear form of the BET isotherm is represented as

$\mathrm{Ce} / \mathrm{qe}(\mathrm{Co}-\mathrm{Ce})=1 / \mathrm{C}_{\mathrm{BET}}+\left(\mathrm{C}_{\mathrm{BET}}-1\right) / \mathrm{q}_{\mathrm{o}} \mathrm{C}_{\mathrm{BET}} \mathrm{Ce} / \mathrm{Co}$

Where CBET $=$ BET adsorption isotherm relating to the energy of the surface interaction. Hematite has been widely used as an adsorbent to remove heavy metal ions from water because of it availability in large quantity and relatively low cost (Zeng et al., 2007, Jeon et al., 2004, Mamindy-Pajany et al., 2009, Mohapatra et al., 2009, Choi et al., 2010, Chen and Li, 2010). But there is little or dearth of information on the adsorption of metallic soaps prepared from locally available oils onto hematite in aqueous media. The present study is focused at studying the adsorption phenomenon (capacity, intensity and energy parameters) of metallic soaps prepared from locally available oils onto hematite in aqueous medium. The research further investigates the applicability of five different isotherm models in interpreting the adsorption process and the role played by both nature ature of soaps and ionic charges.

\section{Nomenclature}

$\mathrm{A}_{\mathrm{T}}=$ Temkin isotherm equilibrium binding constant $(\mathrm{L} / \mathrm{g})$

$\mathrm{b}=$ Langmuir isotherm constant

$b_{K}$ - Khan isotherm model constant

$\mathrm{b}_{\mathrm{T}}$ - Tempkin isotherm constant

$\mathrm{B}_{\mathrm{DR}}$ - Dubinin-Radushkevich isotherm constant

$\mathrm{Ce}$ - equilibrium concentration $(\mathrm{mg} / \mathrm{L})$

Co - adsorbate initial concentration $(\mathrm{mg} / \mathrm{L})$

$\mathrm{C}_{\mathrm{BET}}$ - BET adsorption isotherm relating to the energy of surface interaction $(\mathrm{L} / \mathrm{mg}) \varepsilon$ -

Dubinin-Radushkevich isotherm constant

E - mean free energy $(\mathrm{kJ} / \mathrm{mol})$

$\mathrm{K}_{\mathrm{ad}}$ - Dubinin-Radushkevich isotherm constant (mol2/kJ2)

$\mathrm{K}_{\mathrm{F}}$ - Freundlich isotherm constant $(\mathrm{mg} / \mathrm{g})(\mathrm{dm} 3 / \mathrm{g})^{\mathrm{n}}$ related to adsorption capacity

$\mathrm{K}_{\mathrm{L}}$ - Langmuir isotherm constant $(\mathrm{L} / \mathrm{mg})$

$\mathrm{n}$ - adsorption intensity

qe - amount of adsorbate in the adsorbent at equilibrium $(\mathrm{mg} / \mathrm{g})$

qs- theoretical isotherm saturation capacity $(\mathrm{mg} / \mathrm{g})$

$\mathrm{R}$ - universal gas constant $(8.314 \mathrm{~J} / \mathrm{mol} \mathrm{K})$

$\mathrm{R}^{2}$ - correlation coefficient

$\mathrm{R}_{\mathrm{L}}$ - separation factor $\mathrm{T}$

- Temperature $(\mathrm{K})$

\section{MATERIALS AND METHODS}

\subsection{Sampling}

The adsorbent, metallic ores (hematite; $\alpha-\mathrm{Fe}_{2} \mathrm{O}_{3}$ ) procured from Itakpe, Kogi state, Nigeria (76.9\%) were crushed in laboratory using jaw and roll crushers. Gravimetric method jigging and tabling was employed in removing silineous materials, while magnetic separation method was used in separating magnetic materials from the ore samples. Sieve analyses were performed using British standard sieve plates to obtain sample of hematite 70 micron. Mineralogical analysis of the ore sample was performed with volumetric and spectrophotometric (Buck scientific atomic absorption spectrophotometer model 205A) methods of analysis. Solutions of reagents were prepared with distilled water.- Sodium hydroxide and hydrochloric acid solutions were used for $\mathrm{pH}$ adjustments. $\mathrm{BDH}$ chemical reagents analar grade (of not less than $98 \%$ purity) were used in this study. Determination of specific area (SSA) was done by the ethylene - glycol - monoethyl - ether (EGME) method (Cerato and Luteneger, 2002).

\subsection{Soap Preparation}

Derived adsorbates viz; $\mathrm{AI}^{3+}, \mathrm{Ca}^{2+}$ and $\mathrm{K}^{+}$soaps of butryspermum parkii were prepared by carefully following the method described elsewhere (Tooley, 1976) with slight modification. In this method, 50 $\mathrm{g}$ of shear butter oil was added to each $50 \mathrm{ml}$ of $30 \%$ potassium hydroxide, calcium hydroxide and aluminium hydroxide. $30 \mathrm{ml}$ of ethanol was added into each of the $60 \mathrm{ml}$ beakers, heated at $90^{\circ} \mathrm{C}$ for 1 
hour in a water bath with vigorous stirring until creamy pasty soaps are formed. $50 \mathrm{ml}$ hot saturated sodium chloride solution was then added to each of the pasty soaps with vigorous stirring for 15 minutes and allowed to cool overnight. The soap cakes formed on the surface of the lye were removed, dried and stored in plastic containers.

\subsection{Batch Adsorption Test}

In the reactor tank, the adsorbate/adsorbent interactions were labelled as $\mathrm{AI}^{3+}$ soap/hematite, $\mathrm{Ca}^{2+}$ soap/hematite and $\mathrm{K}^{+}$soap/hematite. These formulations were obtained from a collecting $0.2 \mathrm{~g}$ of hematite into a reactor tank (100 $\mathrm{cm}^{3}$ Erlenmeyer flask). $25 \mathrm{~cm}^{3}$ of each aqueous soap solutions was added. The reaction was enhanced using a mechanical shaker at 120 oscillations per minute followed by centrifuge at $150 \mathrm{rpm}$. Upon filtration of the decanted samples, the filtrate was measured for equilibrium phase concentration $(\mathrm{Ce})$ using the pre designed calibration curve.

The amount of adsorbates adsorbed onto a unit mass of the adsorbent qe in $\mathrm{mg} / \mathrm{g}$ is computed as (Itodo et al., 2012)

$\mathrm{q}_{\mathrm{e}}=\left(\mathrm{C}_{\mathrm{O}}-\mathrm{C}_{\mathrm{e}}\right) \mathrm{V} / \mathrm{W}$

Where $\mathrm{Co}$ and $\mathrm{Ce}$ are the aqueous phase and equilibrium phase dye concentration in $\mathrm{mg} / \mathrm{L}$ respectively. $\mathrm{V}$ is the volume of soap solution $\left(\mathrm{dm}^{3}\right)$ while $\mathrm{W}$ is the adsorbent (Hematite) mass.

The equilibrium data generated were modelled with five different isotherm equations earlier described above.

\section{RESULTS AND DISCUSSION}

\subsection{Results}

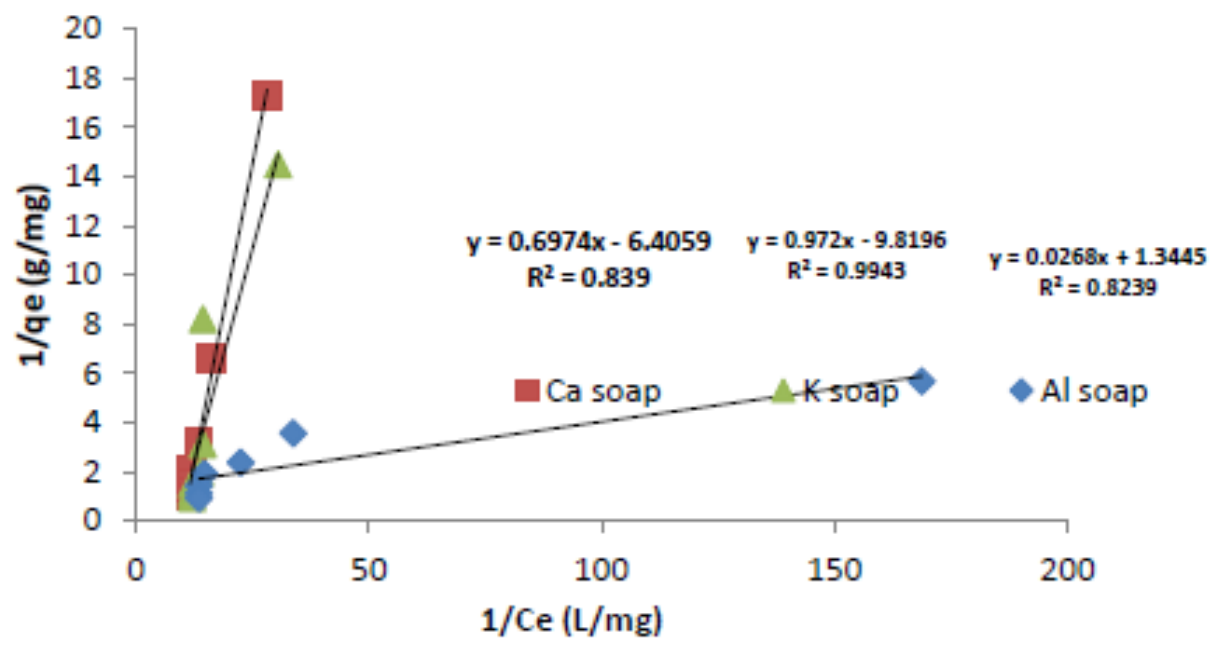

Fig1. Langmuir isotherm for $\mathrm{K}^{+}, \mathrm{Ca}^{2+}$ and $\mathrm{Al}^{3+}$ Soaps of Butyropermum pakii uptake onto Heamatite

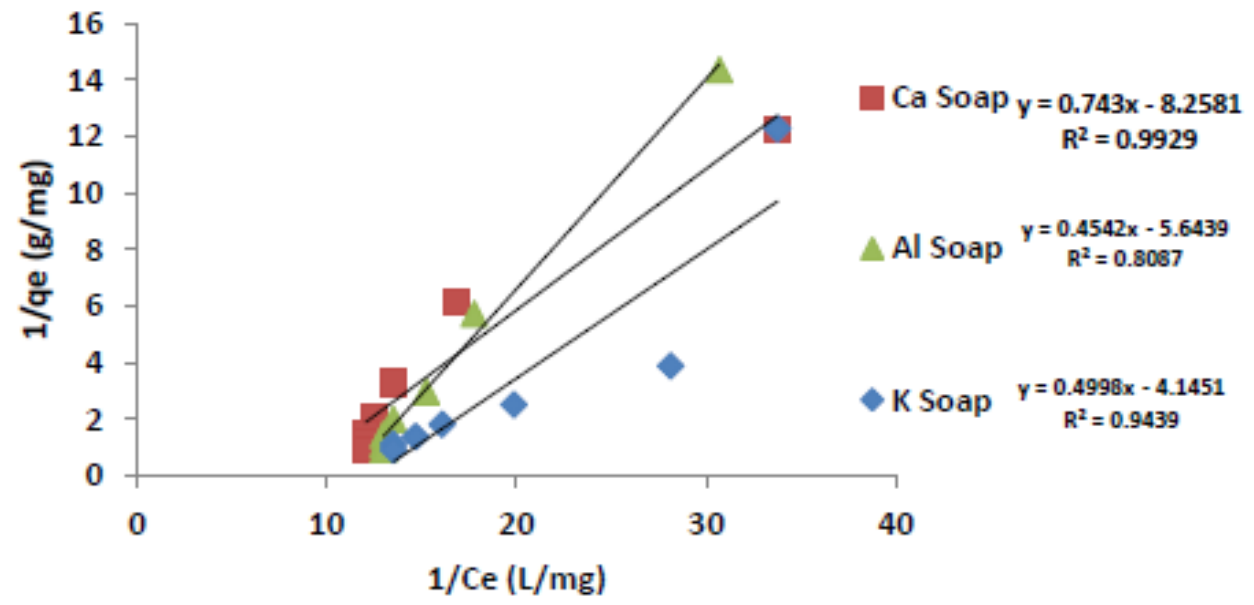

Fig2. Langmuir isotherm for $\mathrm{K}^{+}, \mathrm{Ca}^{2+}$ and $\mathrm{Al} l^{3+}$ Soaps of Hevea brasiliensis uptake onto Heamatite 


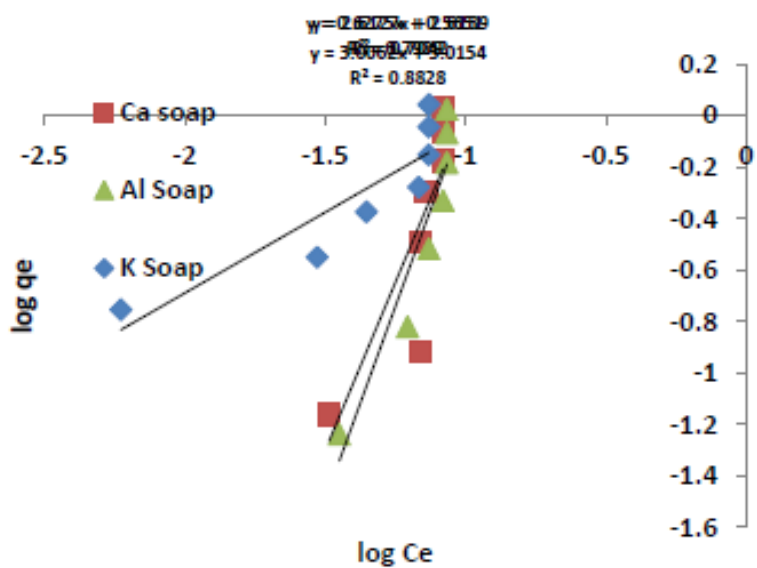

Fig3. Freundlich Isotherm for $\mathrm{K}^{+}, \mathrm{Ca}^{2+}$ and $\mathrm{Al}^{3+}$ Soaps of Butyropermum pakii uptake onto Heamatite

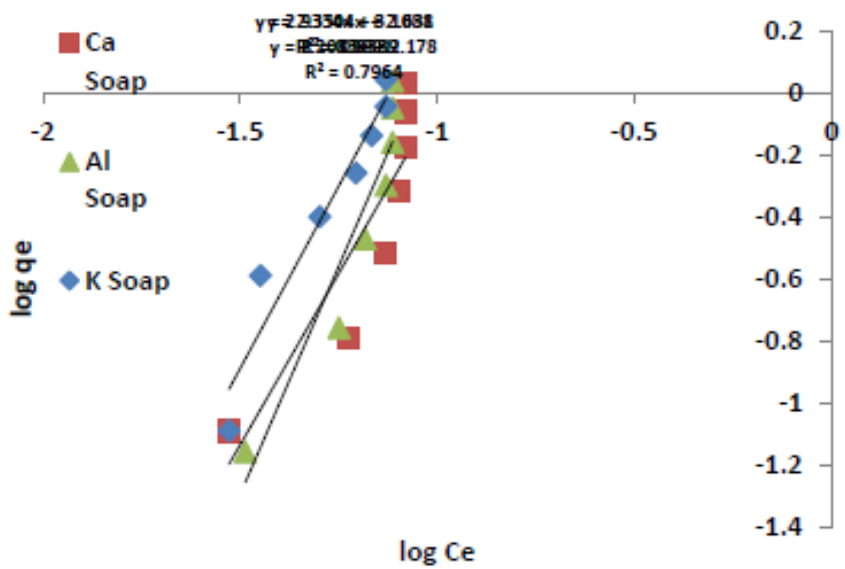

Fig4. Freundlich Isotherm for $\mathrm{K}^{+}, \mathrm{Ca}^{2+}$ and $\mathrm{Al}^{3+}$ Soaps of Hevea brasiliensis uptake onto Heamatite

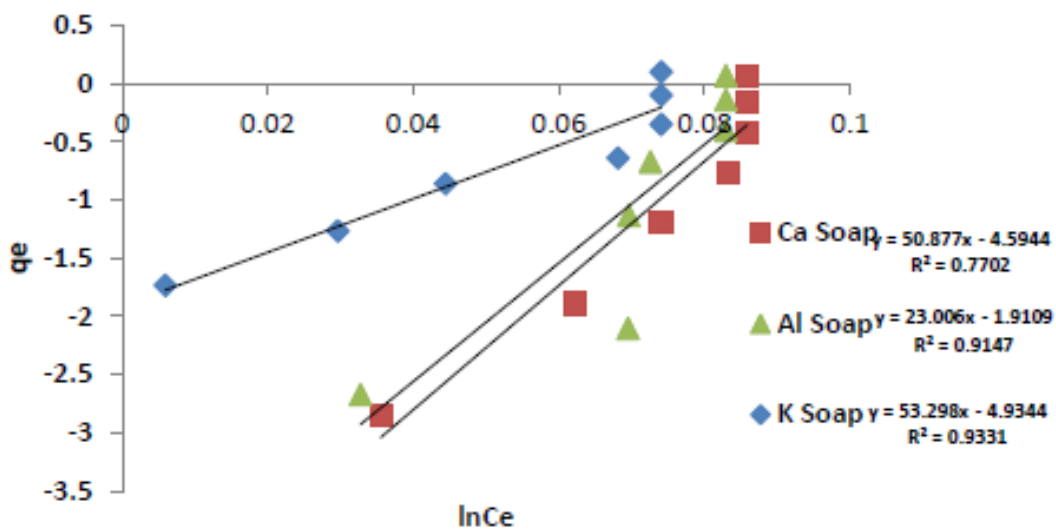

Fig5. Temkin isotherm plot for $\mathrm{K}^{+}, \mathrm{Ca}^{2+}$ and $\mathrm{Al}^{3+}$ Soaps of Butyropermum pakii uptake onto Heamatite

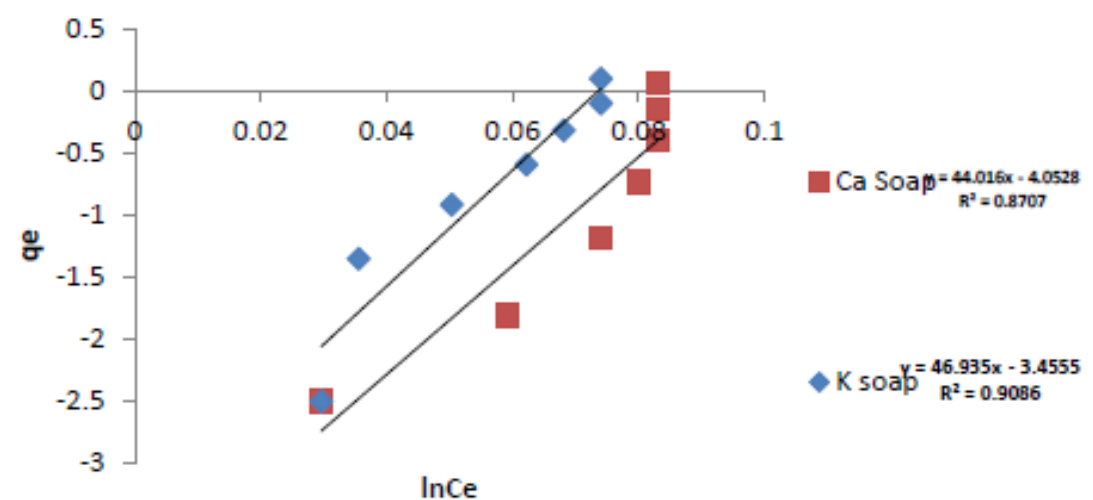

Fig6. Temkin Isotherm plots for $\mathrm{K}^{+}$and $\mathrm{Ca}^{2+}$ Soaps of Hevea brasiliensis uptake onto Heamatite 


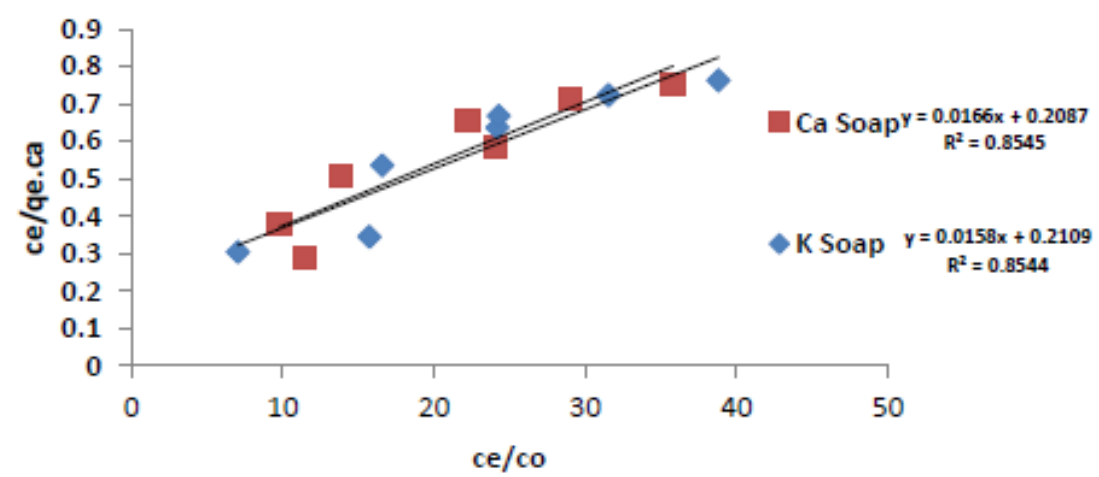

Fig7. BET isotherm plot for $\mathrm{K}^{+}$and $\mathrm{Ca}^{2+}$ Soaps of Butyropermum pakii uptake onto Heamatite

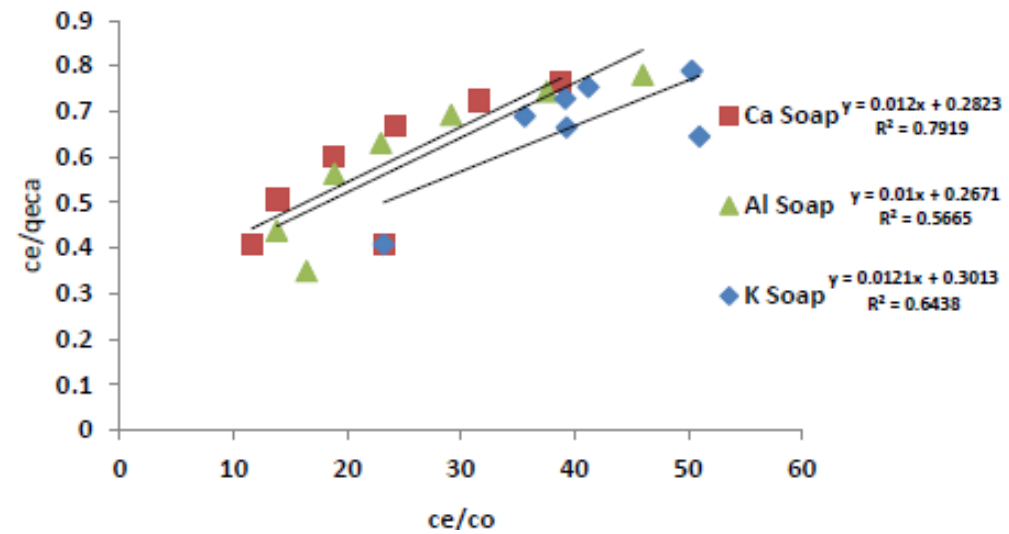

Fig8. BET Isotherm plots for $\mathrm{K}^{+}$and $\mathrm{Ca}^{2+}$ Soaps of Hevea brasiliensis uptake onto Heamatite

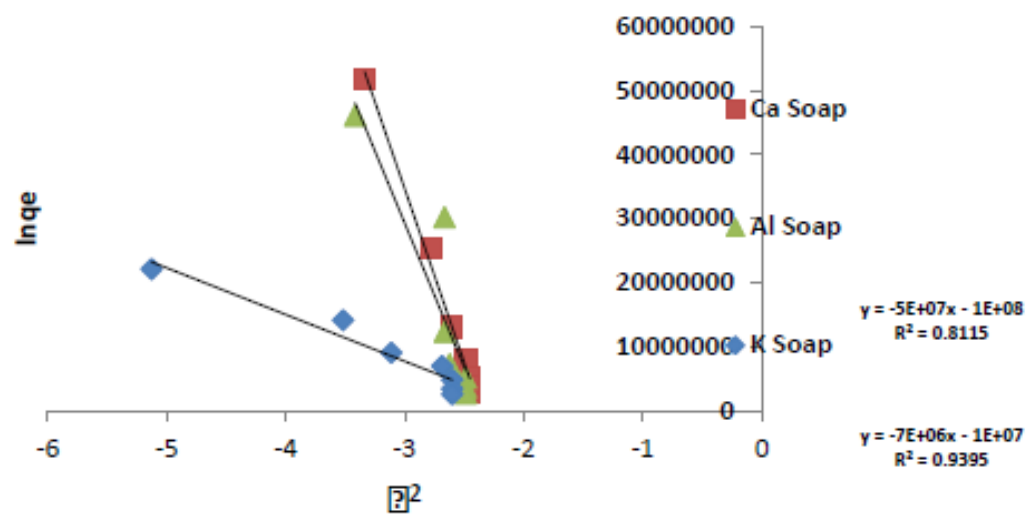

Fig9. Dublin Radushkevich isotherm plot for ${ }^{\mathrm{K}}, \mathrm{Ca}^{2+}$ and $\mathrm{Al}^{3+}$ soaps Butyropermum pakii uptake onto Heamatite

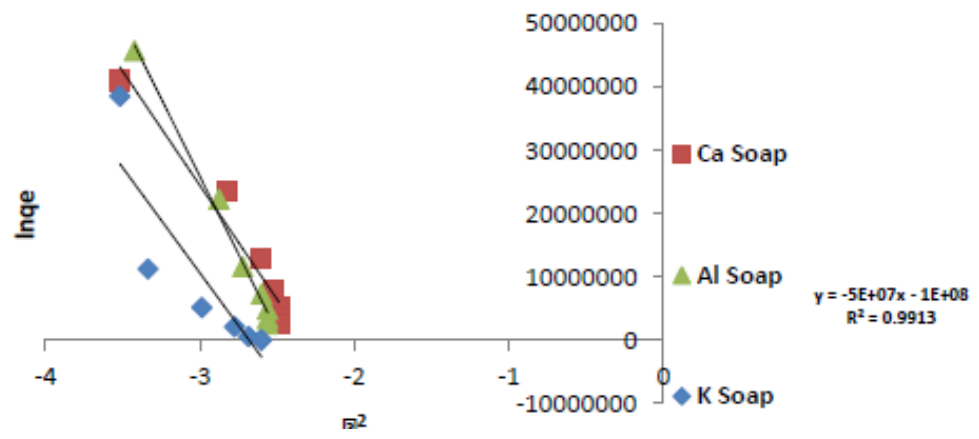

Fig10. Dubinin Radushkevich isotherm plot for $\mathrm{K}^{+}$and $\mathrm{Ca}^{2+}$ Soaps $^{R^{2}=}{ }^{0}$ of ${ }^{7719}$ Hevea brasiliensis uptake onto Heamatite 
Isotherm Studies of Mono, Divalent and Trivalent Cationic Soaps onto Derived $\mathrm{Fe}_{2} \mathrm{O}_{3}$ Adsorbent Surface

Table1. Langmuir experimental data for $\mathrm{K}^{+}, \mathrm{Ca}^{2+}$ and $\mathrm{Al}^{3+}$ soaps of Butryspermum Parkii onto a metal ore

\begin{tabular}{|l|l|l|l|l|}
\hline Metallic soap & Langmuir equation & Linear $\mathbf{R}^{2}$ & \multicolumn{2}{l|}{ Constants } \\
\cline { 3 - 5 } & & & qm Ka & RL \\
\hline $\mathrm{K}^{+}$ & $0.972 \mathrm{x}-9.819$ & 0.994 & 0.102 & 10.086 \\
\hline $\mathrm{Ca}^{2+}$ & & & 0.066 & \\
\cline { 2 - 5 } & $0.697 \mathrm{x}-6.404$ & 0.837 & 0.156 & 9.196 \\
\hline $\mathrm{Al}^{3+}$ & & & 0.072 & 51.696 \\
\cline { 2 - 5 } & $0.026 \mathrm{x}+1.344$ & 0.823 & 0.744 & 0.0134 \\
\hline
\end{tabular}

Table2. Langmuir experimental data for $\mathrm{K}^{+}, \mathrm{Ca}^{2+}$ and $\mathrm{Al}^{3+}$ soaps of Hevea Brasiliensis onto a metal ore

\begin{tabular}{|l|l|l|l|l|}
\hline Metallic soap & Langmuir equation & Linear $\mathbf{R}^{2}$ & \multicolumn{2}{|c|}{ Constants } \\
\cline { 3 - 5 } & & & qm Ka & RL \\
\hline $\mathrm{K}^{+}$ & $0.499 \mathrm{x}-4.145$ & 0.943 & 0.241 & 8.315 \\
\hline $\mathrm{Ca}^{2+}$ & & & 0.0791 & 11.123 \\
\cline { 2 - 5 } & $0.743 \mathrm{x}-8.258$ & 0.992 & 0.121 & 12.444 \\
\hline \multirow{2}{*}{$\mathrm{Al}^{3+}$} & & & 0.0603 & 0.177 \\
\hline
\end{tabular}

Table3. Freundlich experimental data for $\mathrm{K}^{+}, \mathrm{Ca}^{2+}$ and $\mathrm{Al}^{3+}$ soaps of Butryspermum Parkii onto a metal ore

\begin{tabular}{|l|l|l|l|l|}
\hline Metallic soap & Freundlich equation & Linear $\mathbf{R}^{2}$ & \multicolumn{2}{|l|}{ Constants } \\
\cline { 3 - 5 } & & & $\mathbf{n}$ & $\mathbf{K f}$ \\
\hline $\mathrm{K}^{+}$ & $03.006 \mathrm{x}+3.015$ & 0.882 & 0.323 & 1035.142 \\
\hline $\mathrm{Ca}^{2+}$ & $2.612 \mathrm{x}+2.615$ & 0.704 & 0.383 & 412.098 \\
\hline $\mathrm{Al}^{3+}$ & $0.627 \mathrm{x}+0.5650$ & 0.798 & 1.595 & 3.673 \\
\hline
\end{tabular}

Table4. Freundlich experimental data for $\mathrm{K}^{+}, \mathrm{Ca}^{2+}$ and $\mathrm{Al}^{3+}$ soaps of Hevea brasiliensis onto a metal ore

\begin{tabular}{|l|l|l|l|l|}
\hline Metallic soap & Freundlich Equation & \multirow{2}{*}{ Linear $\mathbf{R}^{2}$} & \multicolumn{2}{|l|}{ Constants } \\
\cline { 4 - 5 } & & & n & Kf \\
\hline $\mathrm{K}^{+}$ & $2.208 \mathrm{x}+2.178$ & 0.795 & 0.453 & 150.66 \\
\hline $\mathrm{Ca}^{2+}$ & $2.933 \mathrm{x}+3.108$ & 0.890 & 0.341 & \\
& & & 1282.33 & \\
\hline $\mathrm{Al}^{3+}$ & $2.350 \mathrm{x}+2.638$ & 0.933 & 0.426 & 434.51 \\
\hline
\end{tabular}

Table5. Temkin experimental data for $\mathrm{K}^{+}, \mathrm{Ca}^{2+}$ and $\mathrm{Al}^{3+}$ soaps of Butryspermum Parkii onto a metal ore

\begin{tabular}{|l|l|l|l|l|}
\hline Metallic soap & BET Linear equation & $\mathbf{R}^{2}$ & \multicolumn{2}{l|}{ Constants } \\
\cline { 3 - 5 } & & & b & A \\
\hline $\mathrm{K}^{+}$ & $53.29 \mathrm{x}-4.934$ & 0.933 & 46.92 & 0.910 \\
\hline $\mathrm{Ca}^{2+}$ & $50.87 \mathrm{x}-4.594$ & 0.770 & 48.70 & 0.914 \\
\hline $\mathrm{Al}^{3+}$ & $23.00 \mathrm{x}-1.910$ & 0.914 & 107.72 & 0.920 \\
\hline
\end{tabular}

Table6. Temkin experimental data for $\mathrm{K}^{+}, \mathrm{Ca}^{2+}$ and $\mathrm{Al}^{3+}$ soaps of Hevea Brasiliensis onto a metal ore

\begin{tabular}{|l|l|l|l|l|}
\hline Metallic soap & Temkin equation & Linear $\mathbf{R}^{2}$ & Constants \\
\cline { 3 - 5 } & & & $\mathbf{b}$ & $\mathbf{A}$ \\
\hline $\mathrm{K}^{+}$ & $44.01 \mathrm{x}-4.052$ & 0.870 & 56.295 & 0.919 \\
\hline $\mathrm{Ca}^{2+}$ & $57.46 \mathrm{x}-4.711$ & 0.939 & 43.46 & 0.921 \\
\hline $\mathrm{Al}^{3+}$ & $46.93 \mathrm{x}-3.455$ & 0.0 .908 & 52.79 & 0.929 \\
\hline
\end{tabular}

Table7. BET experimental data for $\mathrm{K}^{+}, \mathrm{Ca}^{2+}$ and $\mathrm{Al}^{3+}$ soaps of Butryspermum Parkii onto a metal ore

\begin{tabular}{|l|l|l|l|l|}
\hline Metallic soap & BET Linear equation & \multirow{2}{*}{$\mathbf{2}$} & \multicolumn{2}{l|}{ Constants } \\
\cline { 3 - 5 } & & & qS & CBET \\
\hline $\mathrm{K}^{+}$ & $0.016 \mathrm{x}+0.208$ & 0.854 & 4.504 & 1.078 \\
\hline $\mathrm{Ca}^{2+}$ & $0.015 \mathrm{x}+0.210$ & 0.854 & 4.446 & 1.071 \\
\hline $\mathrm{Al}^{3+}$ & $0.000 \mathrm{x}+0.711$ & 0.698 & 1.406 & 1.000 \\
\hline
\end{tabular}


Table8. BET experimental data for $\mathrm{K}^{+}, \mathrm{Ca}^{2+}$ and $\mathrm{Al}^{3+}$ soaps of Hevea Brasiliensis onto a metal ore

\begin{tabular}{|l|l|l|l|l|}
\hline Metallic soap & BET Linear equation & $\mathbf{R}^{2}$ & \multicolumn{3}{|l|}{ Constants } \\
\cline { 4 - 5 } & & & CBET & qS \\
\hline $\mathrm{K}^{+}$ & $0.012 \mathrm{x}+0.301$ & 0.643 & 1.039 & 3.197 \\
\hline $\mathrm{Ca} 2+$ & $0.012 \mathrm{x}+0.282$ & 0.791 & 1.043 & 3.400 \\
\hline $\mathrm{Al}^{3+}$ & $0.01 \mathrm{x}+0.267$ & 0.566 & 1.037 & 3.610 \\
\hline
\end{tabular}

Table9. Dubinin Radushkevich experimental data for $\mathrm{K}^{+}, \mathrm{Ca}^{2+}$ and $\mathrm{Al}^{3+}$ soaps of Butryspermum Parkii onto a metal ore

\begin{tabular}{|l|l|l|l|l|}
\hline Metallic soap & D-R Linear equation & $\mathbf{R}^{2}$ & \multicolumn{2}{l|}{ Constants } \\
\cline { 3 - 5 } & & & $\mathbf{B}_{\mathbf{D}}$ & $\mathbf{E}$ \\
\hline $\mathrm{K}^{+}$ & $-5 \mathrm{E}+07 \mathrm{x}-1 \mathrm{E}+08$ & 0.990 & $2.5 \mathrm{E} 7$ & $1.4^{*} 10^{-4}$ \\
\hline $\mathrm{Ca}^{2+}$ & $-5 \mathrm{E}+07 \mathrm{x}-1 \mathrm{E}+08$ & 0.811 & $2.5 \mathrm{E} 7$ & $1.4^{*} 10^{-4}$ \\
\hline $\mathrm{Al}^{3+}$ & $-7 \mathrm{E}+06 \mathrm{x}-1 \mathrm{E}+07$ & 0.939 & $3.5 \mathrm{E} 6$ & $3.78^{*} 10^{-4}$ \\
\hline
\end{tabular}

Table10. Dubinin experimental data for $\mathrm{K}^{+}, \mathrm{Ca}^{2+}$ and $\mathrm{Al}^{3+}$ soaps of Hevea Brasiliensis onto a metal ore

\begin{tabular}{|l|l|l|l|l|}
\hline Metallic soap & D-R Linear equation & \multirow{2}{*}{$\mathbf{R}^{2}$} & \multicolumn{2}{|l|}{ Constants } \\
\cline { 4 - 5 } & & & $\mathbf{B}_{\mathbf{D}}$ & $\mathbf{E}$ \\
\hline $\mathrm{K}^{+}$ & $-4 \mathrm{E}+07 \mathrm{x}-8 \mathrm{E}+07$ & 0.947 & $2.0 \mathrm{E} 7$ & $1.581 * 10^{-4}$ \\
\hline $\mathrm{Ca}^{2+}$ & $-5 \mathrm{E}+07 \mathrm{x}-1 \mathrm{E}+08$ & 0.991 & $2.5 \mathrm{E} 7$ & $1.414^{*} 10^{-4}$ \\
\hline${ }_{\mathrm{Al}} 3+$ & $-3 \mathrm{E}+07 \mathrm{x}-9 \mathrm{E}+07$ & 0.771 & $1.5 \mathrm{E} 7$ & $1.826^{*} 10^{-4}$ \\
\hline
\end{tabular}

\section{DISCUSSION}

This comparative test analysis compares adsorption phenomenon of monovalent $\left(\mathrm{K}^{+}\right)$, divalent $\left(\mathrm{Ca}^{2+}\right)$ and trivalent $\left(\mathrm{Al}^{3+}\right)$ soaps of shea butter oil and rubber seed oil onto hematite. Figure 1showed that the Langmuir equation is best in describing the uptake of $\mathrm{K}^{+}$soap $\left(\mathrm{R}^{2}=0.994\right)$. The value of $\mathrm{R}^{2}$ measures the applicability of the chosen model. A general trend of fitness by Langmuir equation indicates the role played by ionic charge. Hence, it follows that the higher the charge the lower the applicability of Langmuir equation, hence, the lower the extent of monolayer coverage.

Figure 2 has an indication that the type of soap determines the nature of surface coverage as related to the charge. Adsorption of metallic soaps of rubber seed oil is more favourably modelled with Langmuir isotherm i.e rubber seed oil with divalent ions could possibly be uniformly adsorbed onto homogenous surface $\left(\mathrm{R}^{2}=0.992\right)$ than the divalent ion soap of shea butter (Fig. 1) with $\mathrm{R}^{2}$ for the $\mathrm{Ca}^{2+}$ being estimated as 0.839 . Figures 3 and 4 are tests of heterogeneity investigating the use of Freundlich isotherm for different cationic soaps. It is obviously evidenced that the uptake of $\mathrm{K}^{+}$soap us not uniformly distributed unto hematite surface $\left(\mathrm{R}^{2=} 0.882\right)$. This adsorption is in support of heterogeneity (higher $\mathrm{R}^{2}$ ) than those of $\mathrm{Ca}^{2+}$ soap $\left(\mathrm{R}^{2}=0.704\right)$ and $\mathrm{Al}^{3+}\left(\mathrm{R}^{2}=0.798\right)$. There is no order at which ionic charge affect adsorption of soaps of sheabutter oil

In Figure 4, the applicability of Freundlich isotherm is based on charge. $\mathrm{K}^{+}$- soap $(0,796)<\mathrm{Ca}^{2+}$ soap $(0.890)<\mathrm{Al}^{3+}$ - soap $(0.933)$. This implied that the trivalent soap is heterogeniusly attracted to hematite surfacethan the divalent and monovalent soaps. Findings in this research revealed that for the soaps of shea butter oil, the Langmuir equation is best in modelling its adsorption process, having $\mathrm{R}^{2}$ of 0.808 to 0.994 . Figures 5 and 6 describe the Temkin isotherm model for both shea butter oil and rubber seed oil soaps respectively. This model fits so well for $\mathrm{K}+-$ soap $(\mathrm{R} 2=0.933)$ and Al3 + - soap (0.914). It is generally believed that heat of adsorption in the uptake of molecules of these soaps onto hematite layer would decrease linearly rather than logarithmic with coverage (Foo and Hameed, 2010). Figure 6 further supports that heat of adsorption during uptake of $\mathrm{K}^{+}$- soap of rubber seed oil $\left(\mathrm{R}^{2}=0.908\right)$ linearly falls rather than being logarithmic as implied in the Freundlich equation (Ho et al., 2002).

Figure 7 compares the extent at which Bet model can be applicable in explaining adsorption of ionic soaps onto hematite. The same $\mathrm{R}^{2}$ values ().854) were reported for both $\mathrm{K}^{+}$and $\mathrm{Ca}^{2+}$ soaps of shea butter oil. This isotherm shows that the multilayer adsorption prediction for adhering shea butter oil soaps onto hematite is not charge dependent. Figure 8 in contrast to figure 7 is an indication that rubber seed oil soaps adsorption onto hematite is charge dependent with a non-linear trend. Figures 9 and 10 represent the modeling of adsorption experiment using Dubinin Radushkevich isotherm for both rubber seed and shea butter oils soaps. High correlation coefficients or coefficients of 
applicability were reported in both cases. Adsorption in both case are charge dependent without linearity in trends. It is however established in this research that certain energy parameters can be computed for the adsorption of these metallic soaps using the Dubinin Radushkevich isotherm.

A typical adsorption phenomenon is explained using constants deduced from the isotherm plots explained and displayed above. Of more importance are adsorption capacity, intensity, energy values and mode of transport or mechanism. Tables 1 and 2 further adopted Langmuir as favourable. This is demonstrated by the dimensionless constant $\mathrm{R}_{\mathrm{L}}$ commonly known as separation factor ad defined by Webber and Chakkravorti (1974). It is also described as the essential of Langmuir equation. Where $R_{L}=1$ is linear adsorption, $R_{L}>1$ and $R_{L}<1$ are unfavourable and favourable adsorption respectively. In this present research, $\mathrm{R}_{\mathrm{L}}$ values range between 0.013 and 0.079 all depicting favourable adsorption.

Adsorption capacity measurement (qm) follows order for the shea butter oil soaps with a role linked to ionic charge i.e $\mathrm{qm}$ values for $\mathrm{Al}^{3+}(0.744)>\mathrm{Ca}^{2+}(0.156)>\mathrm{K}^{+}(0.102 \mathrm{mmol} / \mathrm{g})$. This trend did not follow for adsorption intensity $\mathrm{Ka}$ though $\mathrm{Al}^{3+}$ soap has the highest (51.096). Tables 3 and 4 are constants deduced from Freundlich plots. Adsorption capacity values are considerably high except for $\mathrm{Al}^{3+}$ shea butter soap (Table 3) whose heterogeneity is faulted since $\mathrm{n}>.1$ A considerably high value was reported for $\mathrm{Ca}^{2+}$ constant representing extent of heterogeneity (n) was investigated. Except for $\mathrm{Al}^{3+}$ shea butter soap $(\mathrm{n}>1)$, the other tends to heterogeneity, $\mathrm{n}<1$ and $1 / \mathrm{n}>1$ being an indication of cooperative adsorption. Hence, the adsorption of hematite is onto a surface of non-uniform energy sites.

Tables 5 and 6 represent constant derived from Tempkin equation. The constants $\mathrm{A}$ and $\mathrm{b}$ are the Temkin isotherm equilibrium bonding $(\mathrm{L} / \mathrm{mmol})$ while $\mathrm{b}$ is the Temkin isotherm constant always greater than unity as obtained in this research. Here, the adsorbent-adsorbate interaction is described by these constants, assessing that the heat of adsorption of all the metallic soap molecule decrease linearly rather than logarithmic as implied in the Freundlich equation.

Tables 7 and 8 relate constants that explain multilayer adsorption. $\mathrm{C}^{\mathrm{BET}}$, being a constant relating energy of surface interaction $(\mathrm{L} / \mathrm{mmol})$ decreases linearly in the ionic charge for shea butter oil soaps $\mathrm{C}^{\mathrm{BET}}$ for $\mathrm{Al}^{3+}$ shea butter soap $(1.00)<\mathrm{C}^{\mathrm{BET}} \mathrm{Ca}$ - soap of shea butter oil $(1.071)<\mathrm{C}^{\mathrm{BET}} \mathrm{K}$ seed oil soaps. For the rubber seed oil soaps, the qm values which measures saturation capacity of rubber increases with increase in ionic charge. Tables 9 and 10 gave constants for Dubinin Radushkevich isotherm which are basically a measure of adsorption energy $\left(B_{D}\right)$ and mean free energy $(E)$. since the mean free energy is obtained from the $B_{D}$, it follows the the energy $E$ for removing a molecule from its location in the sorption space to infinity are considerably low (between $1.414 \times 10^{-4}$ to $3.78 \mathrm{X} 10^{-4}$ $\mathrm{KJ} / \mathrm{mmol}$ ).

\section{CONCLUSION}

Metallic ore (hematite) adsorbent was selected for adsorption of two metallic soaps of shea butter and rubber seed oils. From a generally stand point, adsorption depends on the nature of metallic soaps, ionic charge as well as ionic concentration. This was made evidence by different sorption capacity (qe) values across the different cationic metallic soaps. Results indicate that the adsorbent surface ion is important but in no way a factor for determining the most applicable isotherm. This research unveiled the fact that hematite as adsorbent is as important as others cutting across activated carbon, silica gel, biomasses etc in both application on appropriate adsorbates and in utilizing similar isotherm models for their performance assessment.

\section{REFERENCES}

Abollino, O., Aceto, M., Malandrino, M. 2003. Adsorption of heavy metals on Na-montmorillonite. Effect of pH and organic substances. Water Res., 37, 1619-1627.

Cerato, A. B., Lutenegger, A. J., 2002. Determination of surface area of fine-grained soils by te etylene-glycol-monoethylene ether (EGME) method. Geotech. Test J. 25(3),1-7.

Chen, Y. H., Li, F. A., 2010. "Kinetic Study on Removal of Copper(II) Using Goethite and

Hematite Nano-Photocata-lysts," Journal of Colloid and Interface Science, Vol. 347, No. 2, 277-281. doi:10.1016/j.jcis.2010.03.050.

Choi, W.S., Yang, H. M ., Koo, H.Y., Lee, H.J., Lee, Y. B., Bae, T.S., Jeon, I. C., 2010. "S-mart Microcapsules Encapsu-lating Reconfigurable Carbon Nanotube Cores," Ad-vanced Functional Materials, 20(5)820-825. doi:10.1002/adfm.200901739 
Debnath, S., Ghosh, U. C. 2009. Nanostructured hydrous titanium (IV) oxide: Synthesis, characterization and $\mathrm{Ni}(\mathrm{II})$ adsorption behavior. Chem. Eng. J, 152, 480-491.

Gao, Z., Bandosz, T. J., Zhao, Z. 2009. Investigation of factors affecting adsorption of transition metals on oxidized carbon nanotubes. J. Hazard. Matter., 167, 357-365.

Gunay, A., Arslankaya, E., Tosun, I., 2007. Lead removal from aqueous solution by natural and pretreated clinoptilolite: adsorption equilibrium and kinetics, J.Hazard. Mater. 146, 362-371.

Guo, X, Zhang, S., Shan, S. Q., 2008. Adsorption of metals ions on Lignin. J. hazard. Matter 151, 134-142.

Gu, X., Evans, L. J., Barabash, S. J., 2010. Modelling the adsorption of $\mathrm{Cu}(\mathrm{II})$,

$\mathrm{Cd}(\mathrm{II}), \mathrm{Ni}(\mathrm{II}), \mathrm{Pb}$ (II) and $\mathrm{Zn}$ (II) onto montmorillonite. Geochimica et cosmochimica Acta, 74, 5718-5728.

Hafez, H., Yousef, H., 2012. A study on the use of nano/micro structured goethite and hematite as adsorbents for the removal of $\mathrm{Cr}(\mathrm{III}), \mathrm{Co}(\mathrm{II}), \mathrm{Cu}(\mathrm{II}), \mathrm{Ni}(\mathrm{II})$, and $\mathrm{Zn}(\mathrm{II})$ metal ions from aqueous solutions. International Journal of Engineering Science and Technology (IJEST). 4 (06), 3018-3028.

Hammed, B. H., Din, A.T. M ., Al, A., 2006. Adsorption of Methylene Blue on to Bamboo-Base-d Activated Carbon. Kinetics and Equilibrium Studies. J. Hazard Maters; 141, 819 - 825.

Ho, Y. S., Porter, J. F. and G. Mckay, G., 2002. Equilibrium isotherms studies for the sorption of divalent metal ions onto peat: copper, nickel and lead single component systems. Water, air and soil pollution, 141, 1-33.

Itodo, A. U., Usman, A., Grace, A., Itodo, H. U., Ugboaja, V. C., 2012. Performance Assessment of -Received and Formulated Carbon Animalis: A comparative Adsorption Isotherm Test. Journal of Enviro-nment Protection. (2012) 3(3):288-295. DOI: 10.4236/jep.2012.33036

Jeon, B.H., Dempsey, B. A., Burgos, W. D., Royer, R. A., Roden, E. E., 2004. "Modeling the Sorption Kinetics of Di-valent Metal Ions to Hematite," Water Research, 38(10), 2499-2508. doi:10.1016/j.watres.2004. 03.003

Langmuir, I., 1916, „, The adsorption of gases on plane surface of glass, mica and platinum ${ }^{\text {ee }, J . ~ A m . C h e m . ~ S o c . ~}$ 40, 1361-1368.

Li, Y. H., Ding, J., Zuan, Z., 2003. Competitive adsorption of $\mathrm{Pb}^{2+}, \mathrm{Cu}^{2+}$ and $\mathrm{Cd}^{2+}$ ions from aqueous solution by multiwalled carbon monotubes. Carbon, 41, 2787-2792.

Li, Y. H., Wang, S. Wei, J. 2002. Lead adsorption on carbon monotubes. Chem. Phys. Lett.,357,263-266.

Mamindy-Pajany, Y., Hurel, C., Marmier, N., Romeo, M., 2009. Arsenic adsorption onto Hematite and Geothite,Comptes Rendus Chimie, 12(8), 876-881.

Mecke, K. R., Krim, J.,1996. Adsorption isotherms and thermal fluctuations. Physical Review b 53, (4) 2073202.

Mohapatra, M., Rout, K., Mohapatra, B. K., Anand, S., 2009.' 'Sorption behaviour of Pb(II) and Cd(II) on Iron Ore Slime and Characterization of Metal Ion Loaded Sorbent'. Journal of Hazardous materials, 166, (2-3) 1506-1513.doi:10.1016/j.jhazmat.2008.12.08158

Omer, Y., Altunkaynak, Y., Guzel, F., 2003. Removal of copper, Nickel and Manganese from aqueous solution by Kaolinite. Water Research, 37,948-952.

O’Relly, S. E., Hochella, M. F., 2003. Lead Sorption Efficiencies of natural and synthetic MN and Fe-oxides. Geochim. Cosmichim. Acta., 67,4471-4487.

Citation: E. Etim,et al. "Isotherm Studies of Mono, Divalent and Trivalent Cationic Soaps onto Derived Fe2O3 Adsorbent Surface", International Journal of Advanced Research in Chemical Science (IJARCS), vol. 4, no. 6, pp. 13-22, 2017. http://dx.doi.org/10.20431/2349-0403.0406002

Copyright: () 2017 Authors. This is an open-access article distributed under the terms of the Creative Commons Attribution License, which permits unrestricted use, distribution, and reproduction in any medium, provided the original author and source are credited. 